University of Nebraska - Lincoln

DigitalCommons@University of Nebraska - Lincoln

6-1-1996

\title{
Longitudinal Adjustment Patterns of Boys and Girls Experiencing Early, Middle, and Late Sexual Intercourse
}

\author{
C. Raymond Bingham \\ Michigan State University, rbingham@umich.edu \\ Lisa J. Crockett \\ University of Nebraska-Lincoln, ecrockett1@unl.edu
}

Follow this and additional works at: https://digitalcommons.unl.edu/psychfacpub

Part of the Psychiatry and Psychology Commons

Bingham, C. Raymond and Crockett, Lisa J., "Longitudinal Adjustment Patterns of Boys and Girls Experiencing Early, Middle, and Late Sexual Intercourse" (1996). Faculty Publications, Department of Psychology. 235.

https://digitalcommons.unl.edu/psychfacpub/235

This Article is brought to you for free and open access by the Psychology, Department of at DigitalCommons@University of Nebraska - Lincoln. It has been accepted for inclusion in Faculty Publications, Department of Psychology by an authorized administrator of DigitalCommons@University of Nebraska - Lincoln. 
Published in Developmental Psychology 32:4 (1996), pp. 647-658. Copyright C 1996 by the American Psychological Association, Inc. Used by permission. "This article may not exactly replicate the final version published in the APA journal. It is not the copy of record."

http://www.apa.org/journals/dev/

Submitted March 30, 1994; revised December 8, 1994; accepted February 26, 1995.

\title{
Longitudinal Adjustment Patterns of Boys and Girls Experiencing Early, Middle, and Late Sexual Intercourse
}

\author{
C. Raymond Bingham, Michigan State University \\ Lisa J. Crockett, Pennsylvania State University
}

\begin{abstract}
This study examined the association between psychosocial development and the timing of first sexual intercourse in a sample of White, rural adolescents. Two theoretical models were tested. The first model, derived from problem behavior theory, proposed that earlier timing of first sexual intercourse is associated with longitudinal patterns of transition proneness and poor psychosocial adjustment. The second model, the stage termination model, proposed that early first sexual intercourse interferes with subsequent development, thereby resulting in negative developmental outcomes. problem behavior theory was supported. For both boys and girls, earlier timing of first sexual intercourse was associated with longitudinal patterns of greater transition proneness and poorer psychosocial adjustment. The stage termination model was not supported. No evidence was found suggesting that early timing of first sexual intercourse results in negative psychosocial outcomes.
\end{abstract}

During the current century, adolescents' sexual attitudes and behaviors have changed dramatically, resulting in an increased incidence of adolescent sexual intercourse and a decreased age at first intercourse for both boys and girls (Forrest \& Singh, 1990; Zelnik \& Kantner, 1980). Adolescents' increased participation in sexual intercourse places them at risk for a variety of undesirable physiological outcomes, including unintended pregnancy (Jones et al., 1986; Zelnik \& Kantner, 1980), sexually transmitted disease, and AIDS (Bingham, 1989; Chilman, 1980; D’Augelli \& Bingham, 1993; Zelnik \& Kantner, 1980). The psychosocial consequences of adolescent sexual intercourse, however, are less well understood.

Research has provided consistent evidence of an association between adolescent sexual behavior and several aspects of psychosocial development. Generally, adolescents who initiate sexual intercourse early experience greater psychosocial risk, including more problem behavior and substance use, disrupted family and parental relationships, and poor school performance (Billy, Landale, Grady, \& Zimmerle, 1988; Crockett, Bingham, Chopak, \& Vicary, 1996; Day, 1992; Dorius, Heaton, \& Steffen, 1993; R. Jessor, Costa, Jessor, \& Donovan, 1983; S. L. Jessor \& Jessor, 1977). However, current understanding of the associations between adolescent sexual intercourse and psychosocial development is limited by the crosssectional nature of most of the research conducted to date. In particular, it is unclear whether timing of first sexual intercourse has psychosocial consequences or simply psychosocial correlates. The present research tests these alternatives and extends the existing literature in two ways. First, it moves beyond the prediction offirst sexual intercourse by using a lon- gitudinal design to investigate the antecedent-consequent relation between timing of first intercourse and subsequent psychosocial development. Second, whereas the majority of research on adolescent sex ual behavior has used urban and suburban samples, the present research examines sexual behavior among rural adolescents.

\section{Correlates of Adolescent Sexual Behavior}

\section{Problem Behavior}

Research has consistently identified an association between adolescent sexual behavior and other socially proscribed behaviors. In general, adolescent involvement in deviance, alcohol use and abuse, and illicit drug use has been found to predict earlier first sexual intercourse, both cross-sectionally (Verner \& Stewart, 1974) and longitudinally (Crockett et al., 1996; R. Jessor et al., 1983; S. L. Jessor \& Jessor, 1977; Rosenbaum \& Kandel, 1990). Longitudinal research has indicated that substance use predicts the transition to adolescent sexual involvement (R. Jessor et al., 1983; S. L. Jessor \& Jessor, 1977); however, evidence regarding the temporal sequencing or problem behavior involvement and sexual intercourse is mixed, with some research suggesting that substance use precedes sexual intercourse (R. Jessor et al., 1983; S. L. Jessor \& Jessor, 1977; Mott \& Haurin, 1988; Rosenbaum \& Kandel, 1990), other research suggesting that sexual intercourse precedes substance use (Dorius et al., 1993; Mott \& Haurin, 1988), and still other evidence suggesting that the temporal ordering of substance use and sexual behavior varies by substance (Dorius et al., 1993).

C. Raymond Bingham, Department of Psychology, Michigan State University; Lisa J. Crockett, Department of Human Development and Family Studies, Pennsylvania State University. Corresponding author: C. Raymond Bingham, Department of Psychology, Michigan State University, 135 Snyder Hall, East Lansing, Michigan 48824-1117. Email: bingham@pilot.msu.edu

This research was supported by Grant APR 000933-01, Contract 282-90-0047 awarded to J. R. Vicary by the Office of Adolescent Pregnancy Programs, and by grants from the College of Health and Human Development and the Center for the Study of Child and Adolescent Development at the Pennsylvania State University. We acknowledge Pennsylvania State University for providing the facilities for this research, the students and school personnel who made data collection possible, and the reviewers of the manuscript who provided invaluable feedback. 


\section{Conventional Behaviors}

Educational attitudes and behaviors are associated with adolescent sexual behavior (Billy et al., 1988; Dorius et al., 1993). Greater investment in educational and academic pursuits is related to later initiation (Billy et al., 1988; Hayes, 1987) and lower frequency of sexual intercourse (Ohannesian $\&$ Crockett, 1993). It has also been found that girls' academic aspirations and boys' grades in school decline following first sexual intercourse (Billy et al., 1988). The association between sexual intercourse and academic performance and attitudes may result either from sexually abstinent adolescents spending more time in school activities and less time with members of the opposite sex (Chilman, 1980) or from more educationally motivated students holding less stereotyped sex role images (Cvetkovich, Grote, Lieberman, \& Miller, 1978).

The frequency of church attendance is inversely related to involvement in sexual intercourse (Bingham, Miller, \& Adams, 1990; Crockett et al., 1996; R. Jessor et al., 1983; S. L. Jessor \& Jessor, 1977; Miller, McCoy, Olson, \& Wallace, 1986). Although some evidence suggests that adolescents who experience less religious commitment are more likely to be involved in sexual behavior (Crockett et al., 1996), it also appears that sexual involvement results in decreased religious commitment and less frequent church attendance (Billy et al., 1988).

\section{Social Relationships}

The quality of relationships between parents and their children predicts sexual intercourse. Poorer quality family relationships are associated with more adolescent involvement in sexual behaviors, including necking, petting (Wagner, 1980), and intercourse (Crockett et al., 1996; Rob, Reynolds, \& Finlayson, 1990; Wagner, 1980). In addition, adolescent boys feel less close to their mothers, but not their fathers, following first sexual intercourse (Billy et al., 1988).

Very little is known about the association between the quality of peer relationships and the timing of first sexual intercourse. However, evidence indicates that, following first intercourse, adolescents are more likely to select friends who are also sexually active (Billy et al., 1988).

\section{Psychological Characteristics}

Sexually active adolescents commonly possess a variety of psychological characteristics distinguishing them from their less sexually experienced peers. A number of studies suggest an association between self-esteem and sexual intercourse. Among adults, there is evidence that low self-esteeminterferes with involvement in sexual intercourse (Long, 1976). This is congruent with research indicating that nonvirgin adolescent boys report higher self-esteem than their virgin counterparts (S. L. Jessor \& Jessor, 1977; Wade, 1989), but it does not explain the negative association found between sexual intercourse and the self-esteem of adolescent girls (Day, 1992).

Although some evidence suggests that self-esteem may predict the timing of first intercourse, it is not clear whether involvement in sexual intercourse results in further changes in self-esteem. In either case, it is important to understand the relation between self-esteem and sexual intercourse, because in- creasing self-esteem is the target of a variety of interventions into adolescent sexual and contraceptive behaviors (Watson \& Kelly, 1989). Given the small amount of research on the topic, and the assumption that higher self-esteem is important in the intervention into adolescent sexual behavior, further research is merited.

Negative affect and depression predict less participation and interest in sexual intercourse among adults (Lief, 1986). However, the association between negative affect and adolescent sexual behavior is not well understood. When knowledge regarding adult depression and sexual intercourse is generalized to adolescents, it is anticipated that (a) depressed adolescents are less interested and less involved in sexual intercourse and/or (b) adolescents who begin sexual intercourse early are more likely subsequently to suffer from depression. Further research is needed on this topic.

\section{Gender Issues}

Society has historically maintained a sexual double standard (Reiss, 1960) suggesting that premarital sexual behavior is more permissible for males than for females. Although the sexual double standard has decreased in strength (Clement, 1989; Gagnon, 1977), it still influences sexual socialization, especially among adolescents. This influence is evidenced by gender differences in adolescents' reported age at first sexual intercourse, frequency of intercourse, contraceptive use, and number of sexual partners (Bingham et al., 1990; Zelnik \& Kantner, 1980), as well as their emotional responses to first coitus (Koch, 1988). Because of the differences in socialization existing for adolescent boys and girls, we included gender in the present research so that its moderating effects on the association between timing of first sexual intercourse and psychosocial development could be examined.

\section{Models of Timing and Psychosocial Development}

There are currently no comprehensive theories of adolescent sexuality (Miller \& Fox, 1987). However, problem behavior theory (R. Jessor et al., 1983; S. L. Jessor \& Jessor, 1977) and the stage termination model (Peskin, 1967, 1973) provide direction for the present research.

\section{Problem Behavior Theory}

Problem behavior theory posits that a variety of adolescent problem behaviors and sexual intercourse occur together as a behavioral syndrome. This behavioral syndrome constitutes a state of transition proneness that provides adolescents with a means of achieving otherwise unattainable developmental objectives. Transition proneness is typified by poorer psychosocial adjustment (i.e., more problem behavior and less conventional behavior) and is associated with the timing of developmental transitions (S. L. Jessor \& Jessor, 1977).

Problem behavior theory categorizes psychosocial variables into three domains: the personality system, including the individual's perceptions and feelings about themselves; the perceived environment system, consisting of parental and peer influences; and the behavior system, encompassing problem behaviors such as delinquency and conventional behav- 
iors such as school performance (R. Jessor et al., 1983). In the present research, we examined variables measuring these three domains so that their antecedent-consequent association with the timing of first intercourse could be tested.

\section{The Stage Termination Model}

The stage termination model (Peskin, 1967, 1973) assumes that in each stage of development a minimum level of maturation is necessary in order for successful advancement into the next stage. This model suggests that when transitions occur too early, development is curtailed and negative individual consequences result (Erikson, 1968).

Where sexual intercourse and psychosocial development are concerned, the stage termination model suggests that earlier involvement in sexual activity increases the chances that subsequent development will be compromised. Although it is known that a variety of negative characteristics are associated with early first sexual intercourse (Chilman, 1980; Crockett et al., 1996; Dorius et al., 1993; R. Jessor et al., 1983; S. L. Jessor \& Jessor, 1977; Mott \& Haurin, 1988; Ohannesian \& Crockett, 1993; Rosenbaum \& Kandel, 1990), it is not known whether the timing of first sexual intercourse produces these characteristics or whether they are simply correlates of the timing of first sexual intercourse.

\section{Hypotheses}

The first hypothesis was derived from problem behavior theory, which suggests that transition proneness is associated with poorer psychosocial adjustment and earlier timing of developmental transitions. Hence, the first hypothesis was that longitudinal patterns indicative of poorer psychosocial development (i.e., more problem behavior, less conventional behavior, poorer family and peer relationships, and lower self-esteem and less positive affect [greater depression]) would be associated with earlier timing of first sexual intercourse.

The stage termination model posits that poorer outcomes result when developmental transitions are made too early and individuals are advanced beyond their developmental capability to cope positively. The second hypothesis was that earlier first sexual intercourse would be associated with negative psychosocial outcomes.

The third hypothesis was based on the sexual double standard (Reiss, 1960) and posited that the negative effects of early sexual debut would be greater for girls than for boys.

\section{Method}

\section{Design}

Using a cohort-sequential longitudinal design (Baltes, 1968; Schaie, 1965), we collected the data for the present research to measure three cohorts of adolescents: 7th, 8th, and 9th graders, initially. Each cohort was surveyed annually through 12th grade. Because only two cohorts had data collected before 9th grade, the longitudinal analyses used data collected when the students were in 9th through 12th grades; however, 7th- and 8th-grade data were used to assess psychosocial adjustment before first sexual intercourse, which was included as a covariate.
We pooled data from the three cohorts to maximize the sample size for each grade level; hence, each cohort's 9th-grade data were pooled together, as were their 10th-grade data, and so on through 12th grade. A few students repeated a grade during high school. To maintain the integrity of the design, we assigned the data to consecutive annual waves of the study as though no grade had been repeated. Tests for cohort effects in the pooled data were all nonsignificant, suggesting that the data were not biased by cohort differences.

\section{Sample}

The sample for this study consisted of Euro-American, rural adolescents from a single school district in a geographically contained, middle- to low-income (1980 median household income $=\$ 14,400$; approximately $12 \%$ of all households were below the poverty level) rural community in the northeastern United States. At 9th grade, all participants considered together had a mean age of 14 years $(S D=0.50)$.

Data were collected during regular school hours, with trained research personnel surveying boys and girls in separate rooms. To ensure privacy and maintain confidentiality, we excluded teachers and school administrators from all aspects of the surveying process, identified surveys by a six-digit numerical code, and placed participants in noncontiguous seats while surveys were being filled out. Students who refused consent or whose parents refused consent were excluded from data collection (participation rate was about 95\%).

The total longitudinal sample ( $N=505 ; 251$ girls and 254 boys) included students who participated in the first annual survey, students who completed at least three of the four annual surveys given between their 9th and 12th grades, and students for whom age at first sexual intercourse could be calculated. As a result of inconsistent reporting of sexual intercourse experience, age at first intercourse could not be calculated for 91 of the participants (35 girls and 56 boys). Because the psychosocial adjustment of these 91 adolescents did not differ from the adjustment of those who had complete and consistent sexual behavior data, the adolescents who were missing age at first intercourse data were dropped from analyses.

The remaining sample consisted of 414 participants (216 girls, 198 boys). Ninety-nine of these individuals (47 girls and 52 boys) were missing one of the four surveys given from 9th and 12th grade. Because these students were significantly less well adjusted than their peers who had complete longitudinal data, they were retained in the sample and their missing data were estimated using a method designed to estimate missing data in longitudinal data sets (Petersen, 1987; see also Galambos, Almeida, \& Petersen, 1990). This method imputes missing data by using two components, one nomothetic and cross-sectional, and the other idiographic and longitudinal. The nomothetic component, $\bar{X}_{j}$, is an arithmetic mean obtained from each of the four times of measurement and is calculated as:

$$
\bar{X}_{j}=\frac{1}{N_{j}} \sum_{i} x_{i j}
$$

where $i=$ the $i$ th participant at longitudinal measurement point $j$ who is missing data at a time-point other than $j ; j=$ time-points $\{1,2,3$, $\ldots\}$; and, $N_{j}=$ the number of participants at time $j$ for which data are missing at time-points other than $j$. The idiographic component, $I_{x_{i}}$, is the weighted average distance between each participant's data point and the nomothetic component, calculated as

$$
\bar{I}_{x_{i}}=\frac{1}{K} \sum_{j}\left(x_{i j}-\bar{X}_{j}\right),
$$

where $i=$ the $i^{\text {th }}$ participant at longitudinal time-point $j$ who is missing data at a time-point other than $j ; j=$ time-points $\{1,2,3, \ldots\} ; k=$ the number of longitudinal time-points with non-missing data for $x_{i}$. 
As an example, consider a participant who is missing the third (S3) of four surveys (S1, S2, S3, S4). The nomothetic component is calculated as the mean of variable $x_{i 1}$ measured at $\mathrm{S} 1$ and is based on the subsample of participants who are missing data from a time point other than $\mathrm{S} 1$, and so forth for $x_{i 2}(\mathrm{~S} 2)$ through $x_{i 4}(\mathrm{~S} 4)$. The missing data point is then estimated by adding the idiographic component to the nomothetic component. Because of the prevalence of gender (6 out of 10 measures) and timing group (9 out of 10 measures) differences in psychosocial adjustment, missing data for the present research were estimated separately for boys and girls and for the three timing groups.

To assure that data imputation had not biased the sample, we used LISREL7 (Jöreskog \& Sörbom, 1989) to compare the sample covariance structure before and after imputation in a stacked twogroup (the covariance structures before and after imputation) design with all parameter estimates constrained to be invariant across the two groups (Jöreskog \& Sörbom, 1989). Goodness of fit exceeded .990 , indicating that the covariance structure of the data was not altered by the estimation procedure.

\section{Measures}

Timing of first sexual intercourse. The independent variable was the relative timing of first sexual intercourse. Annual surveys asked participants if they had ever had sex. ${ }^{1}$ The annual data from this question were used, along with chronological age, to calculate each participant's age at first intercourse.

We used age at first sexual intercourse to assign participants to one of three timing groups: early, middle, or late. Timing groups were formed separately for boys and girls, because girls in the sample became sexually active an average of 10 months later than boys. Participants were assigned to the early timing group if they had sexual intercourse before 12th grade $(n=166)$ and their age at first intercourse was below the median age at first intercourse $(M d n$ girls $=15.5$ years of age; $M d n$ boys $=14.75$ years of age). Participants were assigned to the middle timing group $(n=156)$ if they had sexual intercourse before 12th grade and their age at first sexual intercourse was at or above the median. Determination of the median age at first intercourse was based on the subsample of adolescents who had sexual intercourse before 12 th grade. Those who remained virgins at the beginning of 12th grade were assigned to the late timing group $(n=92)$.

The adolescents in the present sample reported a lower median age at first sexual intercourse than adolescents in several notable national samples of urban adolescents, namely, the National Longitudinal Study of Youth, the National Study of Family Growth, and the national surveys of young women and men conducted by Zelnik and Kantner (1980). These three studies show a median age at first sexual intercourse ranging from 17.0 to 17.2 years. This differs markedly from the present study, in which the median age at first sexual intercourse (considering the entire sample) was 16.1 and 15.1 years for female and male adolescents, respectively. However, these three national samples represented earlier cohorts of adolescents (birth years of 1959-1963) than did the sample used in the present research (birth years ranging from approximately 1970 to 1973 ).

Other evidence suggests that the median age of first sexual intercourse for the present sample does not differ from other samples of adolescents from more recent cohorts, which indicate that the age at first sexual intercourse continued to decline during the 1980s (Hofferth, 1987). In addition, $71 \%$ of the adolescents in the present sample reported having had intercourse at least once by the beginning of 12 th grade. This is comparable with national statistics indicating that approximately $80 \%$ of adolescents experience first sexual intercourse by the end of 12th grade (Hayes, 1987). Finally, the age at first intercourse of adolescents in the present sample is comparable with that found in other samples of rural adolescents (Alexander et al., 1989). Taken together, this evidence suggests that the age at first sexual intercourse for adolescents in the present research is similar to those in other rural samples and does not differ greatly from more recent cohorts of nonrural adolescents.

We took several precautions to ensure the validity of the timing of first sexual intercourse measure. First, no age at first intercourse was assigned to participants who reported contradictory longitudinal information regarding their virginity status (e.g., reporting that they were virgins after indicating that they had previously been nonvirgins, or retrospectively reporting an age at first intercourse ${ }^{2}$ that disagreed with their longitudinal reports of intercourse activity), and these participants were excluded from the present analyses. As mentioned previously, the participants who were missing age at first sexual intercourse (91 participants, including those whose longitudinal data were contradictory) did not differ from the remaining sample.

Second, as a check on construct validity, we used analysis of variance to examine the association between timing of first sexual intercourse and other sexual behaviors. Results showed that earlier timing was significantly associated with more necking and petting, $F(2$, $291)=57.26, p<.0001$ and $F(2,291)=50.96, p<.0001$. Further examination of the data indicated that adolescents in the late timing group were more likely than their nonvirgin age-mates to have never necked or petted, whereas all but 2 of the nonvirgins had necked or petted at least once. It is unlikely that adolescents who have had sexual intercourse would not have necked or petted. In addition, it is expected that adolescents who have had sexual intercourse would be more involved than their virgin age-mates in other sexual behaviors. The observation of these expected patterns of association in the present sample provides validity for the timing measure.

\section{Psychosocial Outcomes}

Problem behavior theory guided the selection of outcome measures for the present research. The measures represent the three conceptual systems of problem behavior theory (e.g., R. Jessor et al., 1983): the behavior system (conventional and problem behaviors); the perceived environment system (quality of family and peer relationships); and the personality system (self-esteem and level of affect).

Problem behaviors. Minor deviance was measured by an 11-item scale from the Primary Prevention Awareness, Attitudes and Usage Scale (PPAAUS; Swisher, Shute, \& Bibeau, 1985). The PPAAUS assesses behaviors such as shoplifting, truancy, cheating on exams, staying out all night without parental permission, and fighting. Responses range from $1=$ never to $5=$ almost every day. Scores were computed so that higher scores reflected more minor deviance. On the basis of data from the annual surveys, coefficient alphas ranged from .75 to .81 .

${ }^{1}$ The question regarding the occurrence of sexual intercourse asked the adolescents if they "had ever been sexually active (had sex)." Because of concerns within the participating school district regarding the sexual content of survey items, no more detailed or explicit question was allowed.

${ }^{2}$ The item added at the fourth survey was judged not to be appropriate as a sole indicator of first sexual intercourse for three reasons: (a) it was retrospective, making it inferior to the item measured longitudinally; (b) the retrospective item was asked at different grades in school for members of the three cohorts, making it impossible to use once the data were pooled (see Figure 1); and (c) data for the retrospective item were more frequently missing than were the data for the item asked year to year. 
Substance use was measured by using two single-item measures that were also taken from the PPAAUS. These two items reflected how often participants got drunk and got high on drugs, respectively. Responses to these items ranged from $1=$ never to $5=$ almost every day.

Conventional behaviors. Three single items measured conventional behaviors. The first item measured the frequency of church attendance. Responses ranged from $0=$ never to $5=$ more than once per week. The second item assessed academic expectations by asking participants how much education they planned to complete. Responses ranged from 1 = some high school to $6=$ beyond college. Finally, the third item measured school performance by asking participants to report their average grades (e.g., marks) in school. Responses to this item ranged from $1=$ mostly $F$ 's to $8=$ mostly A's. On the basis of annual survey data, intercorrelations among these items ranged from .51 to .79 .

Quality of relationships. Two multi-item subscales, taken from the Self-Image Questionnaire for Young Adolescents (SIQYA), were used to measure the quality of parent (17 items) and peer ( 9 items) relationships (Petersen, Schulenberg, Abramowitz, Offer, \& Jarcho, 1984). Responses to the scale items ranged from 1 = very strongly agree to $6=$ very strongly disagree. A sample item from the family relationships scale is, "I can count on my parents most of the time," and a sample item from the peer relationships scale is, "I do not have a particularly difficult time making friends." Scale scores were computed so that higher scores indicated more positive relationships. On the basis of the data from the annual surveys, coefficient alphas ranged from .82 to .91 for the family relationships scale and from .89 to .93 for the peer relationships scale. Instrument validity has been demonstrated in prior studies (Petersen et al., 1984).

Psychological adjustment. Psychological adjustment was measured by two multi-item scales assessing self-esteem and positive affect. Self-esteem was measured by the Rosenberg Self-Esteem Scale (Rosenberg, 1965). Items on this scale ranged from $1=$ strongly agree to 4 = strongly disagree. A sample item from this scale is, "On the whole, I am satisfied with myself." Scale scores were computed so that higher scores indicated higher self-esteem. On the basis of data from the annual surveys, coefficient alphas ranged from .85 to .91 . The validity of this widely used instrument has been previously established (Rosenberg, 1965).

Positive affect was measured by the Emotional Tone subscale of the SIQYA (Petersen et al., 1984). Emotional Tone measures positive affect and correlates negatively with depression. Item responses ranged from $1=$ very strongly agree to $6=$ very strongly disagree. An example item from this scale is, "Most of the time I am happy." Scale scores were computed so that a higher score depicted more positive affect. On the basis of data from the annual surveys, coefficient alphas ranged from .82 to .86 . Instrument validity has been demonstrated in prior studies (Petersen et al., 1984).

\section{Results}

Descriptive sample statistics for the 9th- through 12thgrade outcome variables are reported in Table 1. Means broken down by gender and timing of first intercourse groups at each of the four grades are presented in Figures 1, 2, and 3.

The purpose of the present research was to compare two alternative developmental models explaining the association between the timing of first sexual intercourse and psychosocial development. First, assumptions of problem behavior theory were tested by comparing the longitudinal patterns of psychosocial development of adolescents from the timing of first intercourse groups: early, middle, and late. We examined data for the presence and consistency of timing group differences
Table 1

Means, Standard Deviations, and Sample Sizes for Psychosocial Adjustment From 9th Through 12th Grades $(N=414)$

\begin{tabular}{|c|c|c|c|c|}
\hline \multirow[b]{2}{*}{ Variable } & \multicolumn{4}{|c|}{ Grade in school } \\
\hline & 9th & 10th & 11 th & 12 th \\
\hline \multicolumn{5}{|l|}{ Minor deviance } \\
\hline$M$ & 1.68 & 1.68 & 1.70 & 1.68 \\
\hline$S D$ & 0.48 & 0.46 & 0.47 & 0.46 \\
\hline \multicolumn{5}{|l|}{ Drunkenness } \\
\hline$M$ & 1.97 & 2.14 & 2.34 & 2.40 \\
\hline$S D$ & 1.04 & 1.06 & 1.06 & 1.05 \\
\hline \multicolumn{5}{|l|}{ Drug use } \\
\hline$M$ & 1.21 & 1.25 & 1.39 & 1.44 \\
\hline$S D$ & 0.68 & 0.70 & 0.79 & 0.84 \\
\hline \multicolumn{5}{|c|}{ Church attendance } \\
\hline$M$ & 2.77 & 2.51 & 2.26 & 2.05 \\
\hline$S D$ & 1.75 & 1.84 & 1.85 & 1.86 \\
\hline \multicolumn{5}{|l|}{ Academic plans } \\
\hline$M$ & 4.26 & 4.14 & 4.16 & 4.03 \\
\hline$S D$ & 1.47 & 1.42 & 1.37 & 1.30 \\
\hline \multicolumn{5}{|l|}{ Marks in school } \\
\hline$M$ & 6.16 & 6.03 & 6.11 & 6.18 \\
\hline$S D$ & 1.26 & 1.24 & 1.19 & 1.31 \\
\hline \multicolumn{5}{|c|}{ Family relationships } \\
\hline$M$ & 4.55 & 4.57 & 4.50 & 4.53 \\
\hline$S D$ & 0.80 & 0.78 & 0.78 & 0.81 \\
\hline \multicolumn{5}{|c|}{ Peer relationships } \\
\hline$M$ & 4.60 & 4.68 & 4.69 & 4.53 \\
\hline$S D$ & 0.72 & 0.73 & 0.71 & 0.73 \\
\hline \multicolumn{5}{|l|}{ Self-esteem } \\
\hline$M$ & 3.19 & 3.21 & 3.24 & 3.22 \\
\hline$S D$ & 0.50 & 0.50 & 0.48 & 0.55 \\
\hline \multicolumn{5}{|l|}{ Positive affect } \\
\hline$M$ & 4.41 & 4.52 & 4.51 & 4.58 \\
\hline$S D$ & 0.82 & 0.80 & 0.80 & 0.84 \\
\hline
\end{tabular}

in psychosocial development beginning when the participants were in 9th grade, and continuing through 10th, 11th, and 12th grades. These analyses tested whether the timing of first intercourse was associated with longitudinal patterns of poorer psychosocial adjustment.

Second, the hypotheses suggested by the stage termination model were tested by examining the partial association between the timing of first sexual intercourse and psychosocial development measured at 12 th grade. That is, we tested 12th-grade psychosocial functioning for timing group differences while controlling for the level of psychosocial adjustment before first intercourse. These analyses tested the effect of the timing of first intercourse on subsequent psychosocial adjustment.

In all analyses, gender was used as an independent variable, along with timing of first sexual intercourse, so that gender differences in the association between timing of first sexual intercourse and psychosocial development could be tested.

\section{Longitudinal Patterns}

Doubly multivariate analysis of variance (i.e., a repeated measures analysis of variance with multiple dependent variables; D-MANOVA) was used to test the first hypothesis. A 3 (timing group) $\times 2$ (gender) $\times 4$ (grade in school) design was used. Grade in school was the repeated within-subject vari- 
MINOR DEVIANCE

\begin{tabular}{|c|c|c|c|}
\hline \multicolumn{4}{|c|}{ TIMING OF FIRST INTERCOURSE GROUPS } \\
\hline & EARLIEST & MIDDLE & LATEST \\
\hline EMALES & $N=83$ & $N=76$ & $N=50$ \\
\hline MALES & $N=79$ & $N=77$ & $N=39$ \\
\hline
\end{tabular}

\section{DRUNKENNESS}

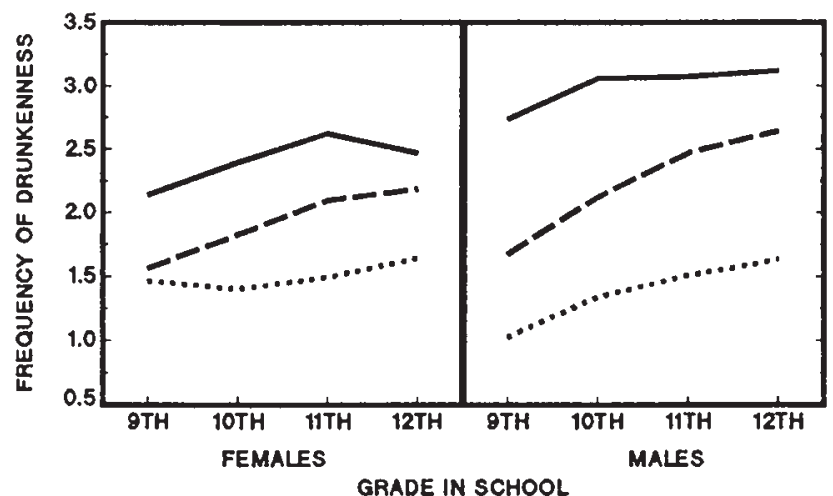

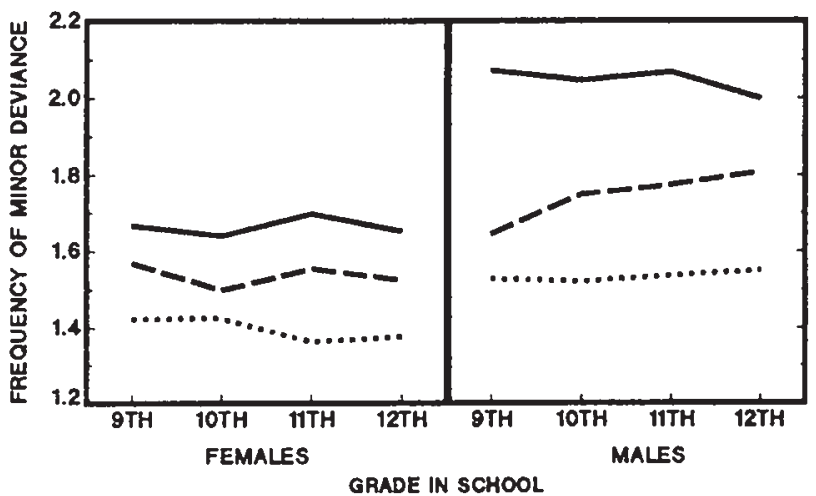

DRUG USE

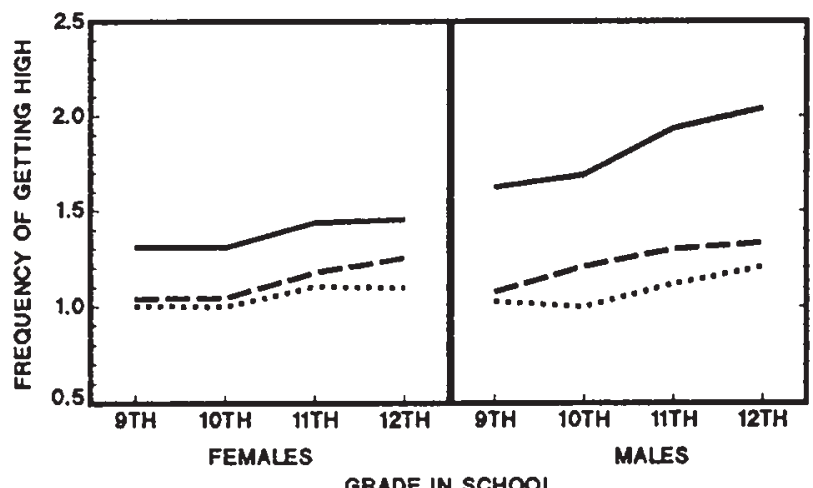

GRADE IN SCHOOL

Figure 1. Frequency of involvement in minor deviance, drunkenness, and drug use from 9th to 12 th grade by gender and timing group.

able. Analyses were conducted for each set of outcome variables: problem behaviors, conventional behaviors, quality of relationships, and psychological adjustment. D-MANOVA results are reported in Table 2 and cell means are presented in Figures 1 through 3.

Problem behavior involvement. D-MANOVA resulted in significant multivariate main effects of gender and timing group, and a significant multivariate interaction of timing and gender (see Table 2). Univariate tests indicated that earlier timing of first sexual intercourse was associated with more minor deviance, drunkenness, and drug use (see Figure 1). The significant multivariate interaction resulted from boys in the earlier timing group consistently reporting more problem behaviors than any other group of girls or boys.

The D-MANOVA also resulted in a significant within-subjects main effect of grade for drunkenness and drug use and a significant within-subjects interaction of grade in school and timing group for drunkenness (see Table 2). Drunkenness and drug use increased from 9th to 12th grade for all three timing groups (see Figure 1).

Conventional behavior. D-MANOVA resulted in betweensubjects main effects of gender and timing (see Table 2). Univariate effects showed one significant gender difference: Girls reported higher marks in school than boys (see Figure 2). Univariate timing group differences were found for church attendance, academic plans, and marks in school. For all three conventional behaviors, participation was greatest for the latest timing group, lower for the middle timing group, and lowest for the earliest timing group.

D-MANOVA also resulted in a significant multivariate within-subjects main effect of grade and a significant interaction of grade and gender. Academic plans increased and church attendance decreased from 9th to 12th grades for all gender and timing groups (see Figure 2). Girls' marks in school increased from 9th to 12th grade, whereas boys' marks remained constant across all four grades, resulting in the interaction of grade and gender (see Figure 2).

Quality of relationships. D-MANOVA resulted in a significant multivariate between-subjects main effect of timing for family relationships and peer relationships (see Table 2). The univariate tests indicated that the quality of family relationships increased and the quality of peer relationships decreased with later first intercourse (see Figure 3). Hence, members of the latest timing group reported the best family relationships, whereas early timing was associated with the best peer relationships. 
CHURCH ATTENDANCE

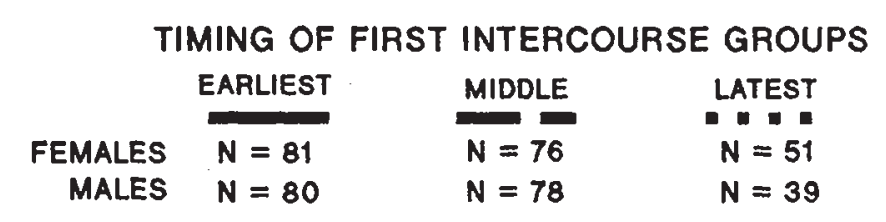

ACADEMIC PLANS

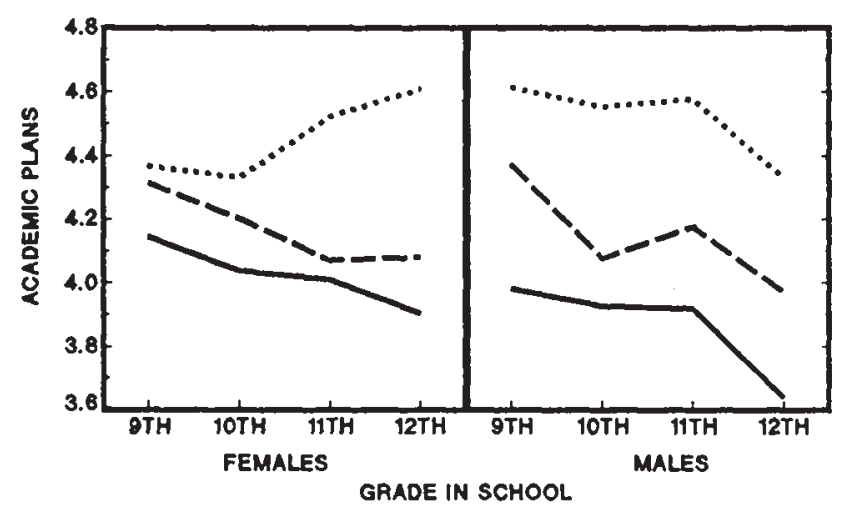

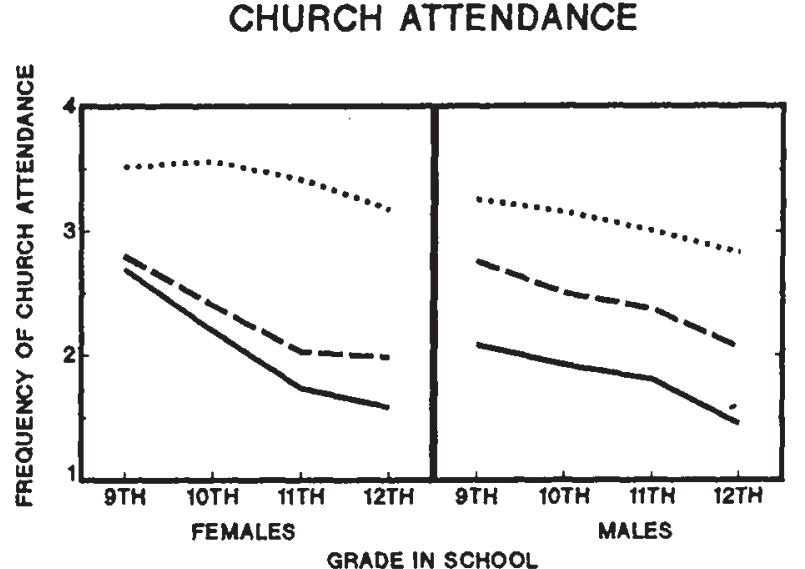

MARKS IN SCHOOL

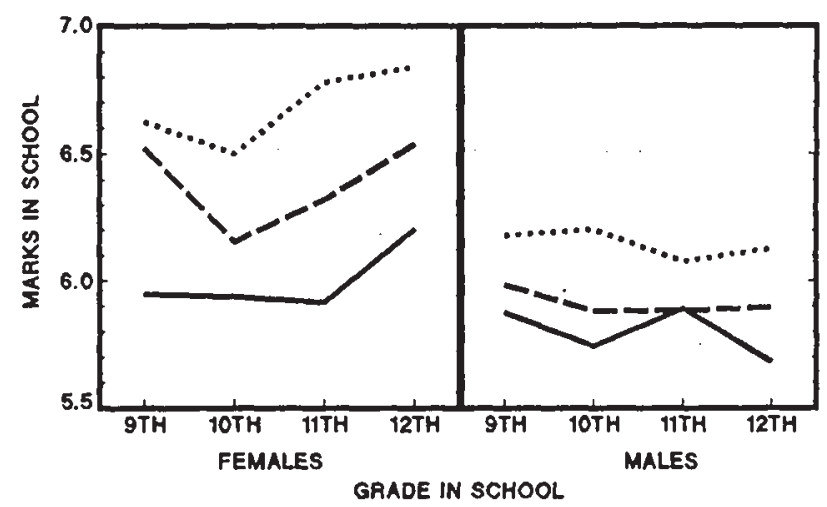

Figure 2. Frequency of church attendance, school aspirations, and marks in school from 9th to 12th grade by gender and timing group.

D-MANOVA also resulted in significant multivariate within-subjects interactions between grade and gender, and between grade and timing group for quality of relationships (see Table 2). Univariate tests indicated that family relationships increased in quality for girls and decreased for boys between 9th and 12th grades. In addition, the pattern of family relationships over time were different for the three timing groups, showing a strong cubic pattern for the middle group that was not evident for the other groups (see Figure 3).

Psychological adjustment. D-MANOVA resulted in a multivariate between-subjects main effect of gender. Univariate analyses indicated that boys reported significantly higher selfesteem and more positive affect compared with girls from 9th to 12th grades (see Table 2). No significant effects of timing group were found for self-esteem or positive affect.

D-MANOVA also resulted in a significant within-subjects interaction of grade and gender for self-esteem (see Table 2). Self-esteem for girls increased steadily from 9th to 12 th grade, whereas the self-esteem of boys did not change significantly. A significant main effect of grade was found for positive affect, which increased significantly between 9th and 12th grades for both girls and boys.
Summary of the longitudinal analyses. The longitudinal analyses demonstrated consistent longitudinal patterns of development associated with the timing of sexual debut. The early timing group had a longitudinal trajectory of poor psychosocial development, whereas members of the middle and late timing groups demonstrated more positive longitudinal patterns of development. These results support the problem behavior theory and suggest that first sexual intercourse is associated with a longitudinal pattern of transition proneness and poorer psychosocial adjustment.

Another question still remains: Is the timing of first sexual intercourse simply part of a pattern of psychosocial development, or, consistent with the stage termination model, is having first sexual intercourse early detrimental to subsequent psychosocial adjustment? The following are analyses testing the second hypothesis.

\section{Outcomes of First Sexual Intercourse}

We tested assumptions of the stage termination model using a 3 (timing group) $\times 2$ (gender) analysis of covariance (ANCOVAs). This design tested the association between the 
TIMING OF FIRST INTERCOURSE GROUPS

$\begin{array}{rlll} & \text { EARLIEST } & \text { MIDDLE } & \text { LATEST } \\ \text { FEMALES } & N=85 & N=77 & N=52 \\ \text { MALES } & N=81 & N=78 & N=39\end{array}$

FAMILY RELATIONSHIPS

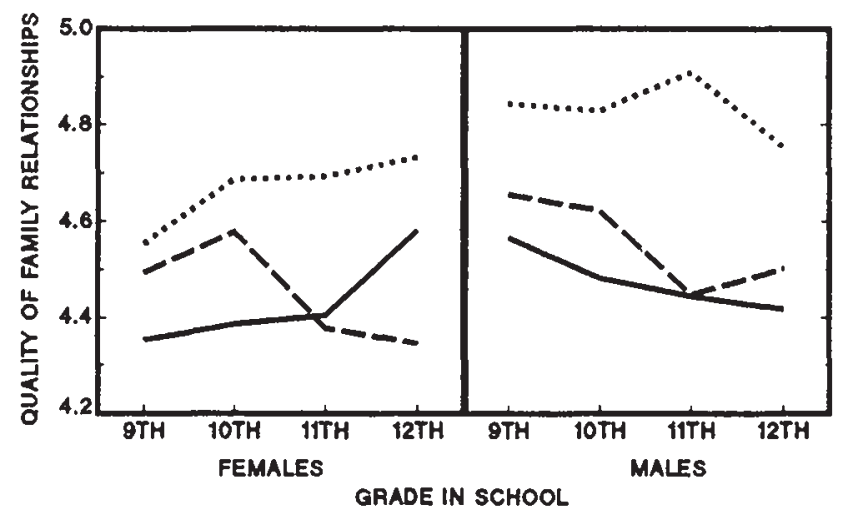

PEER RELATIONSHIPS

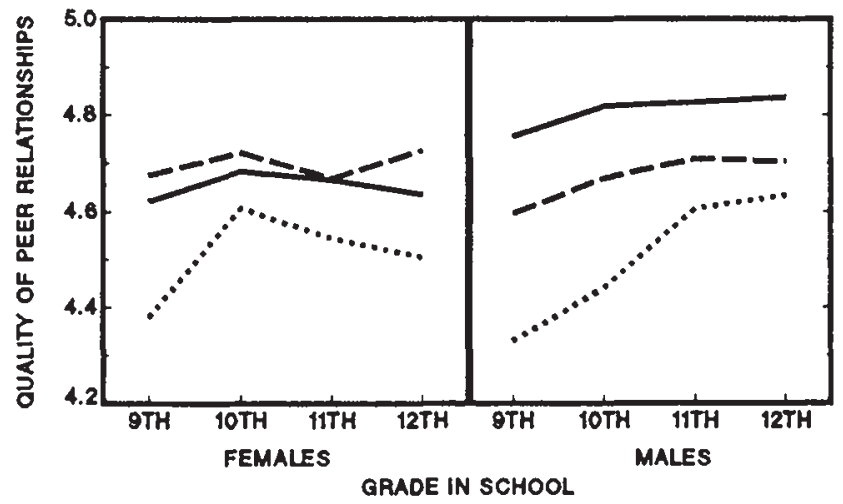

Figure 3. Quality of family and peer relationships from 9th to 12th grade by gender and timing group.

Table 2

Associations Between Timing of First Sexual Intercourse and Longitudinal Patterns of Psychosocial Adjustment

\begin{tabular}{|c|c|c|c|c|c|c|c|}
\hline \multirow[b]{2}{*}{ Psychosocial outcome } & \multicolumn{3}{|c|}{ Between-subjects effect } & \multicolumn{3}{|c|}{ Within-subjects effect } & \multirow[b]{2}{*}{$\begin{array}{c}\text { Grade } \times \\
\text { Timing } \times \text { Gender }\end{array}$} \\
\hline & Timing & Gender & $\begin{array}{l}\text { Timing } \\
\times \text { Gender }\end{array}$ & Grade & $\begin{array}{c}\text { Grade } X \\
\text { Timing }\end{array}$ & $\begin{array}{l}\text { Grade } \times \\
\text { Gender }\end{array}$ & \\
\hline \multicolumn{8}{|l|}{ Problem behaviors } \\
\hline Multivariate $F$ & $30.00^{* * * *}$ & $14.48^{* * *}$ & $3.25^{* *}$ & $13.68 * * *$ & $2.09^{* *}$ & 1.00 & 1.56 \\
\hline Deviance & $36.60^{* * *}$ & $43.57^{* * * *}$ & $4.08^{*}$ & 0.44 & 1.34 & 1.00 & 1.56 \\
\hline Drunkenness & $90.87^{* * * *}$ & $12.06^{* * *}$ & $7.09^{* * *}$ & $36.13^{* * *}$ & $4.20^{* * *}$ & 2.55 & 1.13 \\
\hline Drug use & $36.34^{* * * *}$ & $11.87^{* * *}$ & $5.67^{* *}$ & $10.78^{* * * *}$ & 0.44 & 0.76 & 0.61 \\
\hline \multicolumn{8}{|l|}{ Conventional behaviors } \\
\hline Multivariate $F$ & $7.44^{* * * *}$ & $6.26^{* * * *}$ & 1.18 & $9.37 * * *$ & 0.82 & $2.34^{*}$ & 0.95 \\
\hline Church & $20.17^{* * *}$ & 0.97 & 0.83 & $23.23^{* * *}$ & 1.20 & 1.33 & 0.81 \\
\hline Plans & $6.15^{* *}$ & 0.10 & 0.28 & $3.94^{* *}$ & 0.87 & 2.18 & 0.62 \\
\hline Marks & $7.55^{* * * *}$ & $14.91^{* * * *}$ & 1.03 & 2.30 & 0.47 & $3.39^{*}$ & 1.36 \\
\hline \multicolumn{8}{|l|}{ Quality of relationships } \\
\hline Multivariate $F$ & $9.06^{* * * *}$ & 1.19 & 1.08 & $3.32 * *$ & $1.90^{*}$ & $3.11^{* *}$ & 1.11 \\
\hline Family & $5.92 * *$ & 2.39 & 0.25 & 0.89 & $2.85^{* *}$ & $3.15^{*}$ & 1.29 \\
\hline Peers & $4.09^{*}$ & 0.41 & 1.06 & $5.17^{* *}$ & 0.92 & 1.78 & 0.60 \\
\hline \multicolumn{8}{|l|}{ Psychological adjustment } \\
\hline Multivariate $F$ & 0.50 & $10.48^{* * *}$ & 0.57 & $5.01^{* * *}$ & 0.61 & $3.30^{* *}$ & 0.34 \\
\hline Self-esteem & 0.35 & $15.42^{* * *}$ & 1.10 & 1.79 & 0.38 & $2.95^{*}$ & 0.24 \\
\hline Positive affect & 0.01 & $20.89^{* * * *}$ & 0.70 & $6.93^{* * *}$ & 0.61 & 2.10 & 0.28 \\
\hline
\end{tabular}

${ }^{*} p<.05 . \quad * * p<.01 . \quad * * * p<.001$.

timing of first sexual intercourse and 12th-grade psychosocial adjustment when psychosocial adjustment before first intercourse was statistically controlled. This design was used to examine each of the 10 outcome measures. In each case, two covariates were used. The first was the indicator of prior adjustment, which was measured at the first survey when the participants were in 7th, 8th, and 9th grades. The time lag be- tween the measurement of prior psychosocial adjustment and the measurement of 12th-grade adjustment varied for participants from the three grade cohorts $(6,5$, and 4 years, respectively). The second covariate, grade cohort, was added to the model to control for spurious effects created by these differences in time lag.

In order for analysis of covariance to provide adequate 
statistical control, it is necessary that the covariate be measured before the event being examined (Neter, Wasserman, \& Kutner, 1985). In the present case, that event was first sexual intercourse. Forty-five participants (10 girls, 35 boys) reported that they were nonvirgins when they completed the first survey. For reasons of design integrity, these participants were excluded from the 10 ANCOVAs. Some additional participants were missing at least one of the covariates, resulting in slight fluctuations in the sample size for each of the ANCOVAs.

Results of the ANCOVAs are reported in Table 3. No negative psychosocial outcomes were associated with the timing of first sexual intercourse once prior psychosocial adjustment and grade cohort were statistically controlled. Although significant timing group differences were found for drunkenness, the adjusted means in Table 3 indicate that this effect resulted from the late timing group having a lower level of drunkenness in comparison with the other two timing groups. These results suggest that the timing of first sexual intercourse, per se, is not associated with negative psychosocial outcomes. This is not to say that other factors associated with early sexual intercourse (i.e., unwanted pregnancy, sexually transmitted diseases, or AIDS) do not result in negative psychosocial outcomes.

\section{Gender as a Moderator}

The third hypothesis posited that the effects of early first sexual intercourse would be more severe for girls than for boys. The moderating effect of gender was tested simultaneously with the other hypotheses by examining interactions between gender and timing of sexual intercourse in the D-MANOVAs and ANCOVAs discussed previously. In all, only three interactions of gender and timing group were observed. These interactions were found in the longitudinal association between timing and problem behavior from 9th and 12th grade, and resulted from greater timing group differences for boys than for girls (see Figure 1). Where minor deviance and drug use were concerned, differences between the early and middle timing groups were greater for boys than for girls. For drunkenness, differences among all three timing groups were greater for boys than for girls. Despite these differences in level of problem behavior, longitudinal timing group patterns were the same for both genders; that is, earlier timing was associated with more, and later timing with less, problem behavior at all four grades and for both genders. Although it can be concluded that gender was associated with the strength of the timing effects, it cannot be concluded that the effects of early intercourse are more severe for girls than for boys. Hence, the gender moderation hypothesis was not supported.

\section{Discussion}

The present research tested hypotheses drawn from problem behavior theory, the stage termination model, and the sexual double standard regarding the association between the timing of first sexual intercourse and psychosocial development. Results indicated the following: (a) Earlier first inter- course is associated with poorer psychosocial development, thus supporting problem behavior theory (Bingham et al., 1990; R. Jessor et al., 1983; S. L. Jessor \& Jessor, 1977; Ketterlinus, Lamb, Nitz, \& Elster, 1992); (b) contrary to hypotheses generated from the stage termination model, timing of first sexual intercourse does not result in detrimental psychosocial outcomes; and (c) contrary to hypotheses based on the sexual double standard, the effects of early intercourse are not more severe for girls than they are for boys.

Neither self-esteem nor level of affect were found to be longitudinally associated with the timing of first sexual intercourse. One of two processes may account for this lack of results. First, it may be that the timing of first intercourse is simply not related to self-esteem and level of affect. Second, perhaps other factors, such as socialization and beliefs regarding sex, act independent of timing to shape adolescents' emotional reactions to first intercourse, thus giving rise to a variety of emotional outcomes to having had intercourse that are not directly tied to its timing.

Other results from the present research demonstrated a consistent association between positive psychosocial development and the postponement of first sexual intercourse; however, the quality of peer relationships was an exception. Contrary to hypothesized expectations and other research (Hurrelmann, 1990), adolescents who initiated sexual intercourse the latest had the poorest, rather than the best, quality peer relationships. One explanation of this contradictory finding is that adolescents in the late timing group have difficulty identifying compatible peers (Billy et al., 1988). Adolescents in the late timing group reported the most positive family relationships, the most frequent church attendance, the greatest commitment to education, and the lowest involvement in problem behaviors of any of the three timing groups. Involvement in this constellation of behaviors undoubtedly distinguished these adolescents from their earlier initiating peers. It should be recalled that the present sample consisted of a majority of the adolescents attending a single high school within a single school district, and that the late timing group was the smallest of the three groups in the sample. Because of the small size of this group of adolescents, not to mention their behavioral and interpersonal features, they may have had difficulty finding compatible peers.

A second explanation of the association between timing and peer relationships is that having positive peer relationships may catalyze involvement in problem and sexual behaviors. Having more positive peer relationships may enable adolescents to obtain beer and other substances, help them to identify peers who are willing accomplices in problem behaviors or who are available sexual partners. Having poorer quality family relationships and being less committed to social institutions such as church and school may also disinhibit adolescents, allowing them more freedom to defy the expectations of conventional society (Hirschi, 1969). Thus, positive peer relationships, especially when combined with poor family relationships and low involvement in conventional behaviors, may facilitate adolescents' involvement in problem and sexual behaviors. 
Table 3

Results of Analysis of Covariance: Unadjusted and Adjusted Means for Timing of First Intercourse

\begin{tabular}{|c|c|c|c|c|}
\hline \multirow[b]{2}{*}{$\begin{array}{l}\text { Variable/timing } \\
\text { group }\end{array}$} & \multirow[b]{2}{*}{$\begin{array}{c}\text { Observed } \\
M\end{array}$} & \multicolumn{3}{|c|}{$M$ adjusted } \\
\hline & & $\begin{array}{l}\text { Grade } \\
\text { cohort }\end{array}$ & $\begin{array}{c}\text { Prior } \\
\text { adjustment }\end{array}$ & $\begin{array}{l}\text { Adjustment } \\
\text { \& cohort }\end{array}$ \\
\hline \multicolumn{5}{|l|}{ Minor deviance } \\
\hline Early & $1.79 \mathrm{a}$ & 1.82 & 2.17 & 1.89 \\
\hline Middle & $1.67_{b}$ & 1.67 & 1.52 & 1.56 \\
\hline Late & $1.46_{c}$ & 1.47 & 1.37 & 1.49 \\
\hline \multicolumn{5}{|l|}{ Drunkenness } \\
\hline Early & $2.70_{\mathrm{a}}$ & 2.79 & 3.07 & 2.79 \\
\hline Middle & $2.43_{b}$ & 2.41 & 2.44 & 2.44 \\
\hline Late & $1.64 \mathrm{c}$ & 1.64 & 1.35 & 1.44 \\
\hline \multicolumn{5}{|l|}{ Drug use } \\
\hline Early & $1.71_{\mathrm{a}}$ & 1.80 & 1.66 & 1.72 \\
\hline Middle & $1.30_{\mathrm{b}}$ & 1.28 & 1.38 & 1.32 \\
\hline Late & $1.15_{\mathrm{b}}$ & 1.15 & 1.02 & 1.11 \\
\hline \multicolumn{5}{|l|}{ Church attendance } \\
\hline Early & $1.58_{\mathrm{a}}$ & 1.59 & 2.44 & 2.59 \\
\hline Middle & $2.01_{b}$ & 1.96 & 2.09 & 1.91 \\
\hline \multirow{2}{*}{\multicolumn{5}{|c|}{ Academic plans }} \\
\hline & & & & \\
\hline Early & $3.76_{a}$ & 3.78 & 3.84 & 3.66 \\
\hline Middle & $4.02 \mathrm{a}$ & 4.01 & 4.23 & 3.97 \\
\hline \multirow{2}{*}{\multicolumn{5}{|c|}{ Marks in school }} \\
\hline & & & & \\
\hline Early & $6.07 \mathrm{a}$ & 6.02 & 6.27 & 6.16 \\
\hline Middle & $6.24_{\mathrm{a}, \mathrm{b}}$ & 6.24 & 6.69 & 6.04 \\
\hline Late & $6.52_{\mathrm{b}}$ & 6.48 & 5.47 & 6.72 \\
\hline \multicolumn{5}{|l|}{ Family relationships } \\
\hline Early & $4.57_{a, b}$ & 4.55 & 5.17 & 5.17 \\
\hline Middle & $4.44 \mathrm{a}$ & 4.43 & 4.26 & 3.86 \\
\hline Late & $4.76_{b}$ & 4.76 & 4.43 & 4.91 \\
\hline \multicolumn{5}{|l|}{ Peer relationships } \\
\hline Early & 4.65 & 4.68 & 5.34 & 5.34 \\
\hline Middle & 4.72 & 4.71 & 4.19 & 4.19 \\
\hline Late & 4.58 & 4.58 & 4.48 & 4.49 \\
\hline \multicolumn{5}{|l|}{ Self-esteem } \\
\hline Early & 3.19 & 3.21 & 4.01 & 3.50 \\
\hline Middle & 3.24 & 3.24 & 3.32 & 3.15 \\
\hline Late & 3.24 & 3.24 & 2.49 & 3.08 \\
\hline \multicolumn{5}{|l|}{ Positive affect } \\
\hline Early & 4.56 & 4.59 & 5.62 & 4.71 \\
\hline Middle & 4.59 & 4.59 & 4.56 & 4.52 \\
\hline Late & 4.58 & 4.59 & 3.75 & 4.48 \\
\hline
\end{tabular}

Note. Group means with the same subscripts are not significantly different. Post hoc test results are provided only for effects of timing group that were significant at alpha $<.05$. Values in boldface indicate tests in which timing group effects remained significant after the control variable was covaried.

One of the most important findings from the present research was the consistency of timing group differences in patterns of psychosocial development from 9th to 12th grade. Longitudinal patterns of development for the three timing groups were primarily nonintersecting between 9th and 12th grade (see Figures 1 through 3 ) and represent distinct developmental trajectories. Individuals who had first sexual intercourse early demonstrated the poorest psychosocial adjustment at 9th grade, and the same negative developmental trajectory persisted through 12 th grade. In stark contrast, adolescents in the late timing group had the most positive 9thgrade adjustment and the most positive trajectory of development through 12 th grade.

These patterns of development from 9th to 12th grade were not outcomes associated with the timing of first sexual inter- course, as results presented earlier attest. Instead, they were a continuation of enduring developmental trajectories that preceded 9th grade. Timing group differences in psychosocial development were apparent at the beginning of 9th grade, suggesting that individual trajectories of development were well established by that time (see Figures 1, 2, and 3). Other evidence suggests that individual differences in psychosocial development were a result of childhood variation in variables such as temperament and family context (Jansen, Fitzgerald, Ham, \& Zuckel; 1995; Lambert \& Windmiller, 1977; Patterson, DeBaryshe, \& Ramsey, 1989). These early individual differences are thought to set the stage for later developmental and behavioral patterns that continue into adulthood (Zucker, 1987), resulting in trajectories of development extending from childhood to adolescence, and on to adulthood. 
The consistency of psychosocial development, coupled with the failure to identify any net negative outcomes connected with the timing of first sexual intercourse, implies that the association between poor psychosocial development and early sexual intercourse is not attributable to the timing of first intercourse, per se. Instead, these findings suggest that this association is a continuation of preexisting developmental patterns-patterns that predispose the individual to developmental risks such as unprotected intercourse, sexually transmitted disease, pregnancy, problem behaviors, and isolation from conventional social institutions such as family and school.

Results from the present research provide several implications for intervention into adolescent sexual behavior. First, the longitudinal consistency of timing group differences in psychosocial development suggests that interventions into the sexual behavior of adolescents should protect adolescents from other risks resulting from poor psychosocial development as well. Such risks include substance use and delinquency (R. Jessor et al., 1983; S. L. Jessor \& Jessor, 1977), social alienation (Hirschi, 1969), and the continuation of negative patterns of development (R. Jessor et al., 1983).

Results from the present research also indicate that early intervention into poor psychosocial development might be an efficient means of simultaneously preventing numerous negative developmental outcomes. Enhancing positive psychosocial development during childhood may shift developmental trajectories and effectively prevent entire constellations of negative outcomes during adolescence, including problem behavior involvement and negative outcomes resulting from the failure of young, sexually active adolescents to use safe-sex practices.

The present research examined a sample of Euro-American adolescents attending high school in a rural area of the United States. Future research examining the association between psychosocial development and the timing of first sexual intercourse should focus on other racial and ethnic populations, as well as adolescents who have dropped out of school, or who are experiencing more severe negative adjustment generally. In addition, more research is needed to examine the formation of developmental trajectories and the continuity of these trajectories from childhood, through adolescence, and into adulthood.

In summary, the results of the present research suggest that boys and girls who initiate sexual intercourse early are involved in more problem behavior and less conventional behavior and have poorer quality family relationships. It would also appear that these patterns of negative psychosocial development are not a result of the timing of first sexual intercourse but are a continuation of long-term patterns of poor psychosocial development that were established before ninth grade. On the basis of these results, it is suggested that interventions that enhance childhood psychosocial development might effectively circumvent a host of negative developmental outcomes.

\section{References}

Alexander, C. S., Ensminger. M. E., Kim, Y. J., Smith. J., Johnson, K. E., and Dolan, L. J. (1989). Early sexual activity among adolescents in small towns and rural areas: Race and gender patterns. Family Planning Perspectives, 21, 261-266.
Baltes, P. B. (1968). Longitudinal and cross-sectional sequences in the study of age and generation effects. Human Development, 11, $145-171$.

Billy, J. O. G., Landale, N. S., Grady, W. R., and Zimmerle, D. M. (1988). Effects of sexual activity on adolescent social and psychological development. Social Psychology Quarterly, 51, 190212.

Bingham, C. R. (1989). AIDS and adolescents; Threat of infection and approaches for prevention. Journal of Early Adolescence, 9, $50-66$.

Bingham, C. R., Miller, B. C., and Adams, G. R. (1990). Correlates of age at first sexual intercourse in a national sample of young women. Journal of Adolescent Research, 5, 18-33.

Chilman, C. S. (1980). Adolescent sexuality in a changing American society (Report No. 79-1426). Bethesda, MD: U. S. Department of Health, Education, and Welfare.

Clement, U. (1989). Profile analysis as a method of comparing intergenerational differences in sexual behavior. Archives of Sexual Behavior, 18, 229-237.

Crockett, L. J., Bingham, C. R.,Chopak, J. S., and Vicary, J. R. (1996). Timing of first sexual intercourse: The role of social control, social learning, and problem behavior. Journal of Youth and Adolescence. 25, 89-111.

Cvetkovich, G., Grote, B., Lieberman, E. J., and Miller, W. (1978). Sex role development and teenage fertility-related behavior. $A d-$ olescence, 13, 231-236.

Day, R. D. (1992). The transition to first intercourse among racially and culturally diverse youth. Journal of Marriage and the Family, 54, 749-762.

D'Augelli, T. R., and Bingham, C. R. (1993). Interventions to prevent HIV infection among young adolescents. In R. M. Lerner (Ed.), Early adolescence: Perspectives on research, policy, and intervention (pp. 353-368). Hillsdale, NJ: Erlbaum.

Dorius, G. L., Heaton, T. B., and Steffen, P. (1993). Adolescent life events and their association with the onset of sexual intercourse. Youth and Society, 25, 3-23.

Erikson, E. H. (1968). Youth, identity, and crisis. New York: Norton.

Forrest, J. D., and Singh, S. (1990). The sexual and reproductive behavior of American Women, 1982-1988. Family Planning Perspectives, 22, 206-214.

Gagnon, J. (1977). Human sexualities. Chicago: Scott, Foresman.

Galambos, N. L., Almeida, D. M., and Petersen, A. C. (1990). Masculinity, femininity, and sex role attitudes in early adolescence: Exploring gender intensification. Child Development, 61, 19051914.

Hayes, C. D. (1987). Risking the future: Adolescent sexuality, pregnancy, and childbearing. Washington, DC: National Academy Press.

Hirschi, T. (1969). Causes of delinquency. Berkeley: University ofCalifornia Press.

Hofferth, S. L. (1987). Influences on early sexual and fertility behavior. In C. D. Hayes (Ed.), Risking the future: Adolescent sexuality, pregnancy, and childbearing: Vol. 2. Working papers (pp. 735). Washington, DC: National Academy Press.

Hurrelmann, K. (1990). Parents, peers, teachers, and other significant partners in adolescence. International Journal of Adolescence and Youth, 2, 211-236. 
Jansen, R. E., Fitzgerald, H. E., Ham, H. P., and Zucker, R. A. (1995). Difficult temperament and behavior problems in three- to fiveyear-old sons of alcoholics. Alcoholism: Clinical and Experimental Research, 19, 501-509.

Jessor, R., Costa, F., Jessor, L., and Donovan, J. E. (1983). Time of first intercourse: A prospective study. Journal of Personality and Social Psychology, 44, 608-626.

Jessor, S. L., and Jessor, R. (1977). Transition from virginity to nonvirginity among youth: A social psychological study over time. Developmental Psychology, 4, 473-484.

Jones, E. F., Forrest, J. D., Goldman, N., Henshaw, S., Lincoln, R., Rosoff, J. I., Westoff, C. F., and Wulf, D. (1986). Teenage pregnancy in industrialized countries (pp. 21-36). New Haven, CT: Yale University Press.

Jöreskog, K. G., and Sörbom, D. (1989). LISREL7: A guide to the program and applications (2nd ed.). Chicago: SPSS, Inc.

Ketterlinus, R. D., Lamb, M. E., Nitz, K., and Elster, A. B. (1992). Adolescent nonsexual and sex-related problem behaviors. Journal of Adolescent Research. 7, 431-456.

Koch, P. B. (1988). The relationship of first intercourse to later sexual functioning concerns of adolescents. Journal of Adolescent Research, 3, 345-362.

Lambert, N. M., and Windmiller, M. (1977). An exploratory study of temperament traits in a population of children at risk. The Journal of Special Education, 11, 37-46.

Lief, H. I. (1986). Sex and depression [Special issue: The physician's guide to sexual counseling]. Medical Aspects of Human Sexuality, 20, 38-53.

Long, I. (1976). Human sexuality and aging. Social Casework, 57, $237-244$

Miller, B. C., and Fox, G. L. (1987). Theories of adolescent heterosexual behavior. Journal of Adolescent Research, 2, 269-282.

Miller, B. C., McCoy, K.,Olson, T. D., and Wallace,C. M. (1986). Parental discipline and control attempts in relation to adolescent sexual attitudes and behavior. Journal of Marriage and the Family, 48, 503-512.

Mott, F. L., and Haurin, R. J. (1988). Linkages between sexual activity and alcohol and drug use among American adolescents. Family Planning Perspectives, 20, 128-136.

Neter, J., Wasserman, W., and Kutner, M. (1985). Applied linear statistical models (2nd ed.). Homewood, IL: Irwin.

Ohannesian, C., and Crockett, L. J. (1993). A longitudinal investigation of the relationship between educational investment and adolescent sexual activity. Journal of Adolescent Research, 8, 167182.

Patterson, G. R., DeBaryshe, B. D., and Ramsey, E. (1989). A developmental perspective on antisocial behavior. American Psychologist, 44, 329-335.

Peskin, H. (1967). Pubertal onset and ego functioning. Journal of Abnormal Psychology, 72, 1-15.
Peskin, H. (1973). Influence of the developmental schedule of puberty on. learning and ego functioning. Journal of Youth and Adolescence, 2, 273-290.

Petersen, A. C. (1987, February). Data estimation. Paper presented to the staff of the Developmental Research Methodology Center, Pennsylvania State University, University Park.

Petersen, A. C., Schulenberg, J. E., Abramowitz, R. M., Offer, D., and Jarcho, H. D. (1984). A Self-Image Questionnaire for Young Adolescents (SIQYA): Reliability and validity studies. Journal of Youth and Adolescence, 13, 93-111.

Reiss, I. L. (1960). Premarital sexual standards in. America. New York: Free Press.

Rob, M., Reynolds, I., and Finlayson, P. F. (1990). Adolescent marijuana use: Risk factors and implications. Australian and New Zealand Journal of Psychiatry, 24, 47-56.

Rosenbaum, E., and Kandel, D. B. (1990). Early onset of adolescent sexual behavior and drug involvement. Journal of Marriage and the Family, 52, 783-798.

Rosenberg, M. (1965). Society and the adolescent self-image. Princeton, NJ: Princeton University Press.

Schaie, K. W. (1965). A general model for the study of developmental problems. Psychological Bulletin, 64, 92-102.

Swisher, J. D., Shute, R. E., and Bibeau, D. (1985). Assessing drug and alcohol abuse: An instrument for planning and evaluation. Measurement and Evaluation in Counseling and Development, 17, 91-97.

Verner, A. M., and Stewart, C. S. (1974). Adolescent sexual behavior in middle America revisited: 1970-1973. Journal of Marriage and the Family, 36, 728-735.

Vicary, J. R. (1985). Psychological impact of pregnancy on rural adolescents (Office of Adolescent Pregnancy Prevention, Grant No. APR 000933-01, Contract No. 282-90-0047). Unpublished grant proposal.

Wade, J. T. (1989). A longitudinal analysis of sex by race differences in predictors of adolescent self-esteem. Personality and Individual Differences, 10, 717-729.

Wagner, C. A. (1980). Sexuality of American adolescents. Adolescence, 15, 567-579.

Watson, F. I., and Kelly, M. J. (1989). Targeting the at-risk male: A strategy for adolescent pregnancy prevention. Journal of the $\mathrm{Na}$ tional Medical Association, 81, 453-456.

Zelnik, M., and Kantner, J. F. (1980). Sexual activity, contraceptive use, and pregnancy among metropolitan area teenagers: 19711979. Family Planning Perspectives, 12, 230-237.

Zucker, R. A. (1987). The four alcoholisms: A developmental account of the etiologic process. In P. C. Rivers (Ed.), Nebraska symposium on motivation. 1986: Vol. 34. Alcohol and addictive behaviors (pp. 27-84). Lincoln: University of Nebraska Press. 